\title{
Growth and longevity of the tubeworm Ridgeia piscesae in the variable diffuse flow habitats of the Juan de Fuca Ridge
}

\author{
Istvan A. Urcuyo ${ }^{1,2, *}$, Derk C. Bergquistt ${ }^{1,4}$, Ian R. MacDonald ${ }^{3}$, Mark VanHorn ${ }^{1}$, \\ Charles R. Fisher ${ }^{1}$
}

${ }^{1}$ Department of Biology, The Pennsylvania State University, 208 Mueller Laboratory, University Park, Pennsylvania 16802, USA ${ }^{2}$ Department of Biology, Gettysburg College, 300 North Washington St., Gettysburg, Pennsylvania 17325, USA

${ }^{3}$ Texas A\&M Univ. Corpus Christi, 6300 Ocean Dr. PALS ST320, Corpus Christi, Texas 78412, USA

${ }^{4}$ Marine Resources Research Institute, South Carolina Department of Natural Resources, PO Box 392, Charleston, South Carolina 29412, USA

\begin{abstract}
The hydrothermal vent tubeworm Ridgeia piscesae visually dominates the vent environments in the northeast Pacific. One common vent habitat where $R$. piscesae flourishes is among diffuse vent flow on basaltic substrata. We used chemical analysis of discrete water samples combined with long-term temperature monitoring in 7 aggregations to characterize the immediate habitat of the 'long-skinny' morphotype of $R$. piscesae. We also monitored in situ growth of 536 individuals from 8 separate aggregations. The temperature data show that exposure of most individuals to vent fluid at the plume level is extremely low compared to other previously studied hydrothermal vent tubeworms, which indicates significant microhabitat heterogeneity at small spatial and temporal scales. The growth rates of this morphotype of $R$. piscesae ranged from 0 to $252 \mathrm{~mm} \mathrm{yr}^{-1}$ and were highly variable between individuals in the same aggregation and between different vent sites. However, individual growth rates in consecutive years show no significant difference and are correlated, indicating long-term stability of the sulfide source in some of these aggregations. This study found no significant relationship between initial tubeworm size and corresponding growth rates. The median plume-level temperature in an aggregation was not significantly correlated with growth rate over the entire dataset. In addition, very conservative longevity estimates suggest that this morphotype of $R$. piscesae lives for decades in the hydrothermal vent environments of the Juan de Fuca Ridge.
\end{abstract}

KEY WORDS: Vestimentiferan · Ridgeia · Growth · Tubeworm · Hydrothermal · Juan de Fuca Resale or republication not permitted without written consent of the publisher

\section{INTRODUCTION}

In many hydrothermal vent and cold seep ecosystems, deep-sea tubeworms (Polychaeta, Siboglinidae) are among the dominant megafauna and, due to their obligate endosymbiotic relationship with sulfide-oxidizing chemoautotrophic bacteria, are limited to habitats where hydrogen sulfide is present (Cavanaugh et al. 1981, Felbeck 1981, Childress et al. 1987, Tunnicliffe 1992, MacDonald \& Fisher 1996, Bright et al. 2000). Across the different systems in which they occur, these tubeworms occupy a broad environmental gradient from areas where sulfide-rich fluids emanate as relatively vigorous and continuous diffuse vent flow to areas where vent fluids seep slowly from the seafloor. At one extreme, Riftia pachyptila (from the East Pacific Rise [EPR] vents) lives in relatively strong and continuous diffuse hydrothermal flow, where sulfide availability is high, and dies when vent flow subsides or sulfide levels decrease due to biotic or abiotic factors (Fisher et al. 1988, Hessler et al. 1988, Shank et al. 1998). At the opposite extreme, Lamellibrachia cf. luy- 
mesi (from hydrocarbon seeps in the Gulf of Mexico [GoM]) grows slowly and lives for centuries in environments where exposure to seep fluid is very low (Fisher et al. 1997, Julian et al. 1999, Bergquist et al. 2000).

At the hydrothermal vent sites of the Juan de Fuca Ridge (JdFR) in the northeast Pacific, the tubeworm Ridgeia piscesae inhabits a variety of microhabitats, ranging from relatively high-temperature diffuse flow (up to $\sim 30^{\circ} \mathrm{C}$ ) on sulfide edifices to low-temperature diffuse flow fields (Tunnicliffe et al. 1986, Southward et al. 1995, Sarrazin et al. 1997, Urcuyo et al. 1998). Several morphotypes of $R$. piscesae are found on the JdFR (Tunnicliffe et al. 1986, Black 1991, Southward et al. 1995). One of the $R$. piscesae morphotypes, nicknamed 'long-skinny' because of its slim and elongate body, occurs exclusively in diffuse flow habitats where it is exposed to relatively low-temperature vent flow that issues from cracks in the basaltic substratum. This morphotype occurs in aggregations of hundreds to tens of thousands of individuals that can harbor large communities of associated heterotrophic fauna (Urcuyo et al. 1998). Other morphotypes of this same species typically occur on active sulfide edifices and are exposed to higher temperature vent fluid (Sarrazin et al. 1997). The consistent correlation of some morphotypes with a narrow range of temperature and sulfide regimes suggests that the occurrence of specific morphotypes of $R$. piscesae may be reliable indicators of particular physicochemical conditions (Sarrazin et al. 1997, Urcuyo et al. 1998).

The present study couples intensive year-long temperature monitoring with measurements of tube growth in aggregations of the long-skinny morphotype of Ridgeia piscesae at 3 spatial scales: within aggregations, between aggregations and between vent sites in the JdFR. Since the tubeworms rely on access to sulfide in the vent fluid in order to sustain their obligatory endosymbionts, it is hypothesized that environmental conditions (such as exposure to sulfide from diffuse vent fluid) within the tubeworm aggregations would affect the growth rates of the animals. We determine the growth rates and variability displayed by this morphotype and correlate them to the environmental conditions under which the morphotype occurs. We then relate the measured growth to the spatial and temporal heterogeneity, as well as making conservative estimates of tubeworm longevity in these hydrothermal vent fields.

\section{MATERIALS AND METHODS}

Study sites and tubeworm aggregations. This study was conducted at 3 diffuse-flow vent sites at depths of 2190 to $2200 \mathrm{~m}$ on the Endeavour Segment of the JdFR:
Easter Island (EI), Clam Bed (CB) and a site near the Smoke and Mirrors sulfide edifice (S\&M). EI covers an area of about $200 \mathrm{~m}^{2}$ on the western margin of the Main Endeavour vent field a few meters north of the active sulfide structure 'Peanut' ( $47^{\circ} 56^{\prime} 90^{\prime \prime} \mathrm{N}, 129^{\circ} 06^{\prime} 00^{\prime \prime} \mathrm{W}$ ). There were numerous point sources of shimmering water visible at this site during every visit. Aggregations of the long-skinny morphotype of Ridgeia piscesae, ranging in size from 0.5 to $3.5 \mathrm{~m}$ in diameter, visually dominated the site (Fig. 1). Growth was monitored in 6 groups of tubeworms from this site, 4 of which were also monitored with thermistor arrays (EI-2 through EI-5). EI-4 and EI-5 were at opposite ends of the largest aggregation at EI (Fig. 1A) and, because they were monitored in different years, were treated separately.

The CB vent site (Juniper et al. 1992) was located between the Main Endeavour and High Rise vent fields $\left(47^{\circ} 57^{\prime} 78^{\prime \prime} \mathrm{N}, 129^{\circ} 05^{\prime} 50^{\prime \prime} \mathrm{W}\right.$; Fig. 2). This site was dominated by very large aggregations (up to about $40 \mathrm{~m}$ long by $4 \mathrm{~m}$ wide) of the long-skinny morphotype of Ridgeia piscesae that bound a low-lying sedimented area populated by the vesicomyid clam Calyptogena pacifica. Diffuse shimmering water was visible at many locations within the aggregations and was present in all aggregations monitored at this site. Unlike the other sites, the tubes of most $R$. piscesae here were covered with a dense growth of filamentous bacteria.

The third site (S\&M) was located $50 \mathrm{~m}$ west of EI and just north of the large S\&M sulfide edifice $\left(47^{\circ} 56^{\prime} 53^{\prime \prime} \mathrm{N}, 128^{\circ} 05^{\prime} 55^{\prime \prime} \mathrm{W}\right.$, no mosaic image available from this site) (Delaney et al. 1992, Sarrazin et al. 1997). The largely recumbent long-skinny tubeworms at this location formed a single, low-density aggregation around which there was little evidence of shimmering water.

Thermistor arrays. Each thermistor array consisted of 8 deep-water YSI temperature probes (55000 series), 3 to $4 \mathrm{~m}$ long cables and a pressure-housing unit containing a Tattletale Lite datalogger and batteries. The probes were mounted in pairs (sets) in an inverted 'L-shaped' frame constructed from PVC tubing (Fig. 3). Before and after each deployment each probe was tested and calibrated using NIST-traceable mercury or digital thermometers and a temperaturecontrolled, recirculating water bath. Three criteria were used to evaluate the quality of the thermistor data: (1) the calibration tests, (2) physical inspection of the thermistor arrays including cables and (3) inspection of deployment and recovery temperature records. If a probe did not respond linearly during the calibration test or showed signs of physical damage or did not record temperatures consistent with deployment and recovery through the $2 \mathrm{~km}$ water column then data from that probe were not used. 

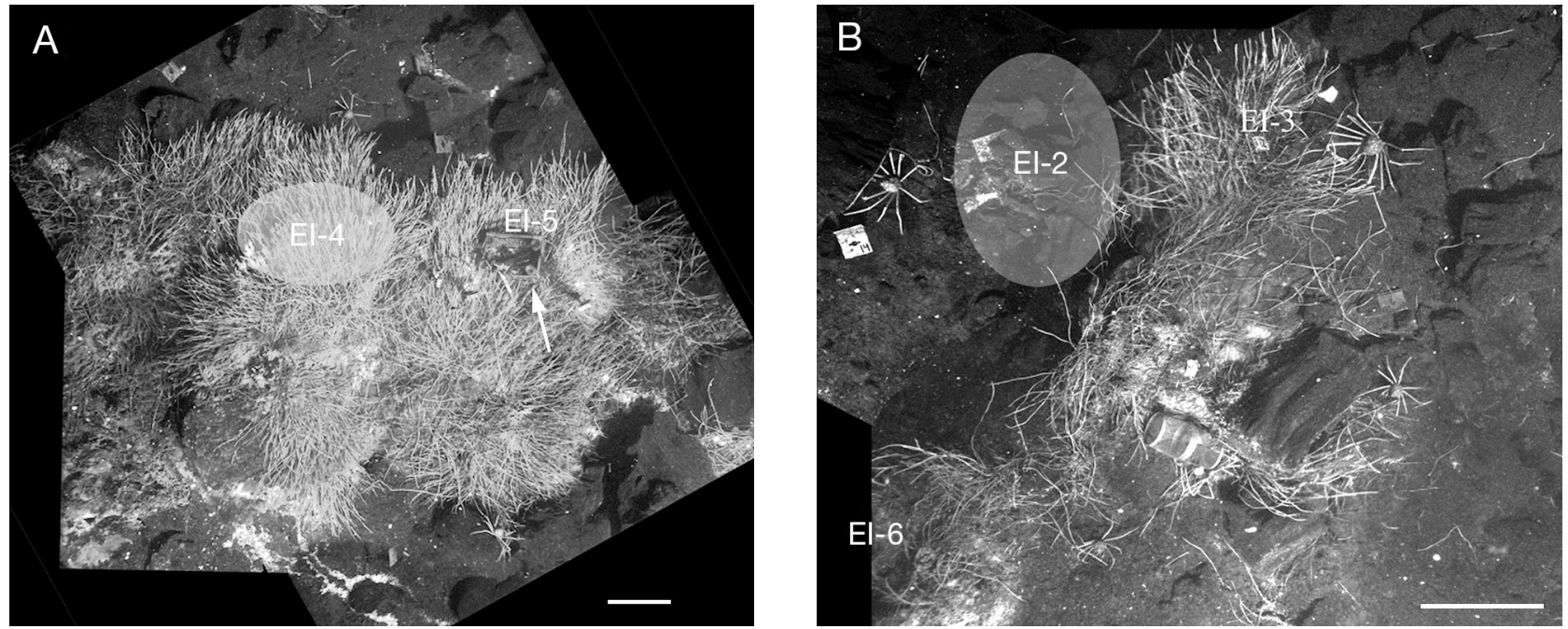

Fig. 1. Ridgeia piscesae. Mosaics of portions of the Easter Island (EI) vent site, indicating the locations of the tubeworm aggregations and thermistor deployments included in this study. (A) Tubeworm aggregation with the EI-4 and EI-5 thermistor arrays and stained tubeworms. At the time of this mosaic, the EI-4 thermistor array had already been collected, but its location is marked on the picture. The white arrow indicates the EI- 5 thermistor array crate. The aggregation is $3.5 \mathrm{~m}$ long and $2.5 \mathrm{~m}$ wide. (B) Mosaic showing the EI-2, EI-3 and EI-6 aggregations. EI-2 and EI-6 were completely collected before these pictures were taken. This diffuse flow area is $6 \mathrm{~m}$ away from the aggregation in the mosaic in (A). Scale bars $=50 \mathrm{~cm}$. View heading (up) is approximately south

The thermistor L-shaped frames were specifically designed such that the top probe in each pair would be located among the tubeworm plumes (their primary gas exchange organ) when the bottom probe was placed near the putative source of diffuse flow, among

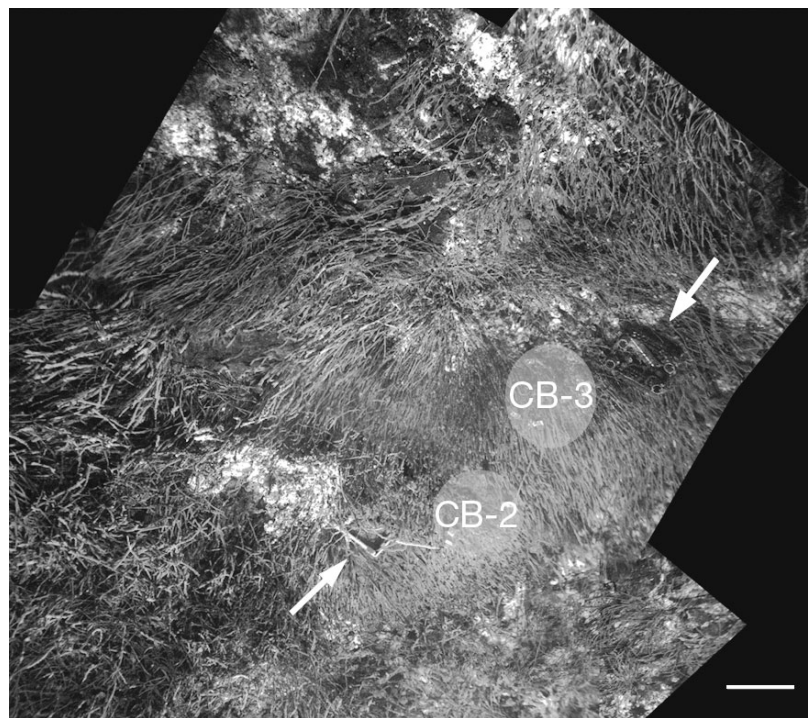

Fig. 2. Ridgeia piscesae. Mosaic of a portion of the Clam Bed (CB) vent site, indicating the locations of the CB-2 and CB-3 tubeworm aggregations and thermistor deployments (white arrows). White areas within the tubeworm aggregation indicate thick covering of bacterial mats. Scale bar $=50 \mathrm{~cm}$. View heading (up) is approximately west the crowded posterior ends of the worms. The positions of the plume-level probes within each aggregation were documented with video and $35 \mathrm{~mm}$ cameras immediately after deployment and before recovery. The exact placement of the base-level probes was

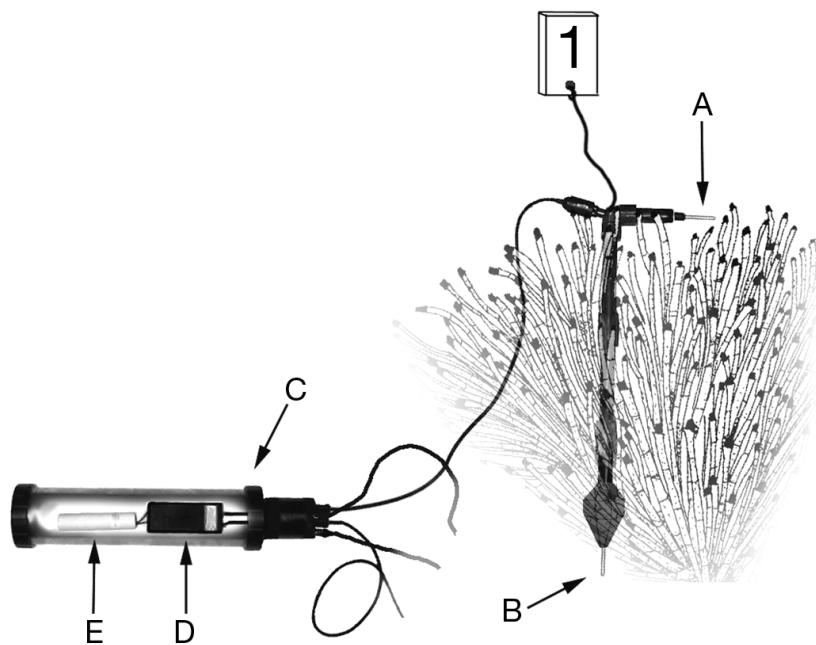

Fig. 3. Thermistor array deployment. The inverted 'L-shape' of the thermistor set can be seen with the top temperature probe located at the plume level and the bottom temperature probe located at the base level of the tubeworm Ridgeia piscesae aggregation. The electronic datalogger and batteries are inside the cylindrical pressure housing (deployment and recovery plastic crate not shown). A: plume-level probe; B: base-level probe; C: pressure housing; D: tattletale datalogger; E: lithium batteries 
often obscured by the tubeworms in the aggregations. If video- or photo-records indicated that a probe had been moved between deployment and recovery, the corresponding data were not used.

Temperature data analysis. After the retrieval of each thermistor array, the temperature records (date, time and temperature) were immediately downloaded into a personal computer and stored. In order to make comparisons between arrays with respect to exposure of tubeworms to vent fluid, data from each thermistor are reported as the differences between the individual temperature measurements and ambient temperatures. Ambient water temperature was determined for each thermistor from the lowest temperature recorded by the thermistor before deployment at the site or immediately after recovery (while the array was traveling with the research vehicle on the bottom). Before analysis of the temperature records, the first and final 24 to $48 \mathrm{~h}$ periods were purged from the datasets to avoid temperatures recorded during the deployment and retrieval activities of the research vehicle.

Because all the temperature datasets used for this study showed significant deviations from a normal distribution (Ryan-Joiner test: $\mathrm{p}<0.001$ ) and linear transformations failed to normalize the data, nonparametric statistics were used to describe the data. Year-long medians for the different probes (plume level and base level) were log-transformed and utilized in a fully nested ANOVA in which vent site and aggregation within site were random factors. Temperature probe medians were used instead of the full dataset to avoid violating the assumption of no autocorrelation in the general linear model. Temperature measurements from S\&M were not included in this analysis, since only a single aggregation was monitored at that site. When vent site was a significant factor in the model, aggregation median temperatures were used as single observations in an F-test to compare the different sites; when aggregation within site was significant, all data points were used and aggregations were compared using a Kruskal-Wallis test.

Vent fluid hydrogen sulfide determination and analysis. During the 1999 field season, 18 water samples were taken from around the EI and CB tubeworm aggregations using a modified syringe-based water sampler. The device consisted of 4 hydraulic pistons that could be actuated individually from inside the submersible; each piston was attached to a dampening spring and to a $10.0 \mathrm{ml}$ gastight syringe in such a way that upon actuation, the plunger of the syringe was pulled back, drawing in the water sample. Each syringe drew water through approximately $5 \mathrm{~m}$ of small-bore $(0.025 \mathrm{~cm}$ diameter) PEEK tubing with a dead volume of $1.5 \mathrm{ml}$. The intake of each of the PEEK sample tubes was fixed to the low-level temperature probe of the submersible, which could be positioned by the manipulator arm allowing simultaneous collection of temperature measurements and water samples from the same point. Before each dive, the PEEK tubing was filled with deoxygenated distilled water and the syringes were loaded with $0.7 \mathrm{ml}$ of a zinc acetate solution $(5: 1,2.6 \%$ zinc acetate: $6 \% \mathrm{NaOH})$ to prevent spontaneous oxidation of sulfide in the sample. Once aboard the ship, the water samples were kept on ice and sulfide was released with phosphoric acid ( $43 \% \mathrm{H}_{3} \mathrm{PO}_{4}$ by volume) immediately before a $1.0 \mathrm{ml}$ sub-sample was injected into a HP 5890 Series II gas chromatograph (Childress et al. 1984). Sulfide concentrations in each sample were detected via a thermal conductivity detector and quantified using a HP 3396 Series II Integrator calibrated with a premixed calibration gas. Linear regression analysis was used to determine the relationship between temperatures and corresponding sulfide concentrations for the $\mathrm{EI}$ and $\mathrm{CB}$ vent sites.

Tubeworm staining and growth. To determine tubeworm growth rates, tubeworms in 10 aggregations were stained between 1994 and 1998 (Table 1) using an in situ staining apparatus manipulated by the research submersibles (Urcuyo et al. 1998, 2003, Bergquist et al. 2000). Anterior tube growth is readily apparent the following year as white tube increments above the blue- or red-stained section (Urcuyo et al. 2003, Van Dover \& Lutz 2004). Some animals were stained blue one year and red the following year, resulting in double-stained individuals with a bluestained region, a red-only-stained region (1st year's growth) and new white increments (2nd year's growth) if they grew in both years.

Tubeworms were collected at the end of each study period either directly using the manipulators of the research vehicle (ROV 'ROPOS' or DSV 'Alvin') or using a custom-built collection device ('Bushmaster Jr.'; Bergquist et al. 2002, Urcuyo et al. 2003). Once on board ship, all stained individuals were separated from the collection and anterior tube inner diameter (ID), posterior tube outer diameter (OD) and linear tube growth were measured using calipers. Individual tube growth was measured as the distance between the anterior end of the tube and the previous year's stain mark; these measurements were standardized to a yearly growth rate $\left(\mathrm{mm} \mathrm{yr}^{-1}\right)$ based on the actual time between staining and collection of the tubeworms (0.9 to $2.2 \mathrm{yr}$ ). Because the long-skinny morphotype of Ridgeia piscesae is typically anchored to the basaltic substratum (or each other), their tubes often break near the point of attachment during collection and the entire tube is not recovered. Tube length was measured by tracing the length of the tube from anterior 
Table 1. Ridgeia piscesae. Growth studies and thermistor array deployments in the Endeavour Segment of the Juan de Fuca Ridge, 1994 to 1999. A range in the collection date column indicates multiple collections from the same aggregation (Agg.). Growth interval: elapsed time period from the time of staining to the time of collection. * : time period elapsed between the blue and red staining; n/a: a thermistor array was not available to monitor temperature in these aggregations

\begin{tabular}{|c|c|c|c|c|c|c|}
\hline Site & Agg. & Stain color & $\begin{array}{l}\text { Staining date } \\
\text { (dd/mm/yy) }\end{array}$ & $\begin{array}{l}\text { Collection date } \\
\text { (dd/mm/yy) }\end{array}$ & $\begin{array}{c}\text { Growth interval } \\
\text { (yr) }\end{array}$ & $\begin{array}{l}\text { Thermistor } \\
\text { deployment }\end{array}$ \\
\hline $\mathrm{S} \& \mathrm{M}$ & SM-1 & Blue & $10 / 08 / 96$ & $12 / 09 / 97$ & 1.1 & 1996-1997 \\
\hline \multirow{7}{*}{ Easter Island } & EI-1 & Blue & $13 / 07 / 94$ & $12 / 07 / 95$ & 1.0 & $\mathrm{n} / \mathrm{a}$ \\
\hline & EI-2 & Blue & $15 / 07 / 95$ & $13 / 09 / 97$ & 2.2 & 1996-1997 \\
\hline & EI-3 & Blue & $15 / 07 / 95$ & $15 / 09 / 97$ & 2.2 & $\mathrm{n} / \mathrm{a}$ \\
\hline & EI-4 & Blue & $13 / 09 / 97$ & 07/08/98 & 0.9 & $1997-1998$ \\
\hline & EI-5 & Blue & $15 / 09 / 97$ & 19/08/99 & $0.9^{*}, 1.9$ & \\
\hline & & + Red & $01 / 08 / 98$ & $19 / 08 / 99$ & 1.1 & 1998-1999 \\
\hline & EI-6 & Blue & $15 / 09 / 97$ & 07/08/98 & 0.9 & $\mathrm{n} / \mathrm{a}$ \\
\hline \multirow[t]{4}{*}{ Clam Bed } & CB-1 & Blue & $24 / 08 / 96$ & $02-06 / 08 / 98$ & $1.1^{*}, 2.0$ & \\
\hline & & + Red & $14 / 09 / 97$ & $02-06 / 08 / 98$ & 0.9 & 1997-1998 \\
\hline & CB-2 & Blue & 02/08/98 & $27-28 / 08 / 99$ & 1.1 & 1998-1999 \\
\hline & CB-3 & Blue & 06/08/98 & $30 / 08 / 99$ & 1.1 & 1998-1999 \\
\hline
\end{tabular}

end to the point of posterior breakage with a piece of twine (total tube length), and initial tube length was calculated as the difference between total tube length and new tube growth. Of a total of 536 stained tubeworms collected over the course of this study, 179 were intact to a posterior outer diameter (POD) of $1.2 \mathrm{~mm}$ or less and these animals were used in analyses of the relationship between total tube length and growth. The assumption that this subset of organisms is a valid representation of the actual total length of the organism in situ is warranted because measurements on the few fully intact animals indicated that the distance from the point of attachment to a POD of $1.2 \mathrm{~mm}$ is $<1 \mathrm{~cm}(0.8 \mathrm{~cm}, \mathrm{SD}=0.08 \mathrm{~cm}, \mathrm{n}=13)$.

A fundamental assumption of the present study is that the tube growth in this morphotype of Ridgeia piscesae accurately represents eventual biomass growth by the individual. Typically, the anterior sections of the tubes of this particular morphotype are filled with the plume and vestimentum tissues (the gas exchange organ and muscular section below it) of the organism, while the posterior tube sections are small in diameter, cylindrical in shape, thin-walled and transparent. The posterior sections contain trunk tissue and include the terminal opisthosome (posterior-most section of the tubeworm body) very near the end of their closed-ended tubes (Urcuyo et al. 2003). These small-diameter posterior extensions of tube and body are not found in other morphotypes of $R$. piscesae living in higher vent flow regimes on the JdFR or found in other vent tubeworms from the EPR (I. A. Urcuyo \& C. R. Fisher pers. obs.).

Time-lapse tube growth documentation. As a pilot study, a time-lapse still-photography system (Martell et al. 2002) was deployed in July 1994 and documented a group of stained tubeworms at the Easter Island site (EI-1) for $1 \mathrm{yr}$. The camera took one $35 \mathrm{~mm}$ color picture every $7 \mathrm{~h}$ over the deployment period. Following recovery the images were digitized for analysis. Tube growth was followed on 4 stained tubeworms that were oriented approximately parallel to the plane of the picture. These animals were easily identifiable and were tracked individually between frames. New tube growth was measured on the images in pixels and converted to millimeters using the anterior tube outer diameter of that individual for scale and Image Tools software (Ver. 1.25). The anterior tube outer diameter was assigned a value of $5 \mathrm{~mm}$ based on the average anterior tube outer diameter of 6 individuals collected from this aggregation at the end of the study (this diameter does not change appreciably in animals of these lengths in a single year).

Tubeworm growth analyses. The study sites and the aggregations included in this study were selected chiefly by their accessibility and ease of maneuverability by the research vehicles around them as well as their visual characteristics (healthy looking tubeworms and presence of shimmering water indicating vent fluid mixing within the aggregation). This resulted in an uneven number of aggregations when comparing the $\mathrm{CB}$ and EI sites, with a corresponding loss of statistical power in the analysis. The growth data were transformed $\left(y^{1 / 2}\right)$ prior to analysis to satisfy the assumptions of a general linear model. Linear and nonlinear regressions were used to examine the relationship between tubeworm total tube length and growth rate. Due to the lack of significant or consistent relationships between tube length and growth rate, tube length was not used as a covariate in any further statistical treatments of the growth data. Growth rate data 
were analyzed using a fully nested ANOVA with site (EI and CB) and aggregation within site as random factors. When a significant vent site effect was found $(p<0.05)$, aggregation means were used as individual observations in an F-test to compare EI and CB. When significant aggregation within vent site effects was found, Tukey-Kramer pairwise comparisons were used to compare growth rates between individual aggregations. Two-sample $t$-tests were used to test for significant differences between consecutive years in growth rates of double-stained individuals.

\section{RESULTS}

\section{Physical and chemical environment}

Thermistor records showed that temperatures fluctuated rapidly and varied between different areas within individual aggregations (Table 2, Fig. 4). Temperatures recorded at the plume level were generally just above ambient (Table 2). Median temperatures recorded by plume-level probes were 0.05 to $0.85^{\circ} \mathrm{C}$ above ambient, and two-thirds of the medians were

Table 2. Plume-level and base-level temperature anomalies (relative to ambient) recorded by the thermistor arrays deployed within 7 aggregations of Ridgeia piscesae. Ambient water temperature was determined by the lowest temperature recorded for each thermistor set immediately before deployment or after recovery. Negative minimum temperatures represent lower values recorded during the monitoring time (always $<0.05 \%$ of the total temperature measurements from that thermistor). Agg.: tubeworm aggregation; Max. ${ }^{*}$ : maximum temperature anomaly recorded within the lower $99 \%$ of the record

\begin{tabular}{|c|c|c|c|c|c|c|c|c|c|c|}
\hline \multirow[t]{2}{*}{ Agg. } & \multirow[t]{2}{*}{ Set } & \multicolumn{3}{|c|}{ - Temp. $\left({ }^{\circ} \mathrm{C}\right)-$} & \multirow{2}{*}{$\begin{array}{l}\text { Median } \\
\text { temp. }\left({ }^{\circ} \mathrm{C}\right)\end{array}$} & \multicolumn{5}{|c|}{ — Percent below or equal (above ambient): } \\
\hline & & Min. & Max. & $\operatorname{Max}^{*}$ & & $0.02^{\circ} \mathrm{C}$ & $0.1^{\circ} \mathrm{C}$ & $0.2^{\circ} \mathrm{C}$ & $0.5^{\circ} \mathrm{C}$ & $1^{\circ} \mathrm{C}$ \\
\hline \multicolumn{11}{|c|}{ Plume-level } \\
\hline \multirow{4}{*}{ SM-1 } & 1 & -0.01 & 1.49 & 0.79 & 0.10 & 14.3 & 52.1 & 81.6 & 98.2 & 99.98 \\
\hline & 2 & -0.08 & 0.95 & 0.95 & 0.12 & 5.2 & 40.6 & 75 & 97.2 & 100 \\
\hline & 3 & -0.06 & 1.76 & 1.15 & 0.13 & 8.0 & 35.9 & 72.3 & 96.9 & 99.8 \\
\hline & 4 & -0.07 & 1.71 & 1.15 & 0.11 & 11 & 45.9 & 76 & 97.1 & 99.8 \\
\hline \multirow[t]{2}{*}{ EI-2 } & 5 & -0.05 & 2.09 & 1.18 & 0.10 & 10.5 & 56.1 & 90 & 98.4 & 99.8 \\
\hline & 6 & -0.07 & 7.67 & 6.5 & 0.27 & 3.9 & 13 & 36.1 & 76.7 & 89.3 \\
\hline \multirow[t]{3}{*}{ EI-4 } & 7 & -0.06 & 0.82 & 0.48 & 0.06 & 19.6 & 73.7 & 93.5 & 99.9 & 100 \\
\hline & 8 & -0.03 & 0.79 & 0.53 & 0.08 & 14.1 & 73.6 & 94.9 & 99.8 & 100 \\
\hline & 9 & -0.06 & 0.51 & 0.36 & 0.05 & 30.8 & 77.9 & 96.8 & 99.99 & 100 \\
\hline \multirow[t]{2}{*}{ EI-5 } & 10 & -0.04 & 1.53 & 1.07 & 0.06 & 14.8 & 68 & 91.1 & 98.2 & 99.9 \\
\hline & 11 & 0.0 & 2.3 & 1.25 & 0.12 & 0.3 & 38.3 & 77 & 95.6 & 99.6 \\
\hline \multirow[t]{2}{*}{ CB-1 } & 12 & -0.04 & 5.55 & 5.17 & 0.50 & 1.3 & 7.1 & 20.7 & 50.3 & 67.2 \\
\hline & 13 & -0.1 & 1.09 & 0.78 & 0.15 & 8.4 & 31.2 & 62.1 & 97.4 & 99.97 \\
\hline \multirow[t]{2}{*}{ CB-2 } & 14 & 0.0 & 2.68 & 1.83 & 0.25 & 0.1 & 6.7 & 33.1 & 92.6 & 99.3 \\
\hline & 15 & 0.0 & 2.86 & 0.63 & 0.19 & 0.3 & 13.7 & 57.4 & 99.6 & 99.99 \\
\hline \multirow[t]{3}{*}{ CB-3 } & 16 & 0.0 & 5.68 & 4.3 & 0.61 & 0.05 & 1.6 & 11.6 & 40.6 & 74.7 \\
\hline & 17 & 0.04 & 6.03 & 4.6 & 0.85 & 0.0 & 0.4 & 4.3 & 24.2 & 61.8 \\
\hline & 18 & 0.01 & 2.98 & 2.3 & 0.53 & 0.02 & 1.7 & 12.9 & 46.6 & 85.5 \\
\hline \multicolumn{11}{|c|}{ Base-level } \\
\hline \multirow[t]{4}{*}{ SM-1 } & 1 & -0.02 & 8.87 & 8.65 & 2.24 & 0.4 & 4.9 & 13.6 & 27.3 & 36.2 \\
\hline & 2 & -0.08 & 3.00 & 1.77 & 0.19 & 5.5 & 23.3 & 54.7 & 93.8 & 99.3 \\
\hline & 3 & 2.22 & 14.83 & 14.35 & 4.95 & 0.0 & 0.0 & 0.0 & 0.0 & 0.0 \\
\hline & 4 & -0.08 & 4.42 & 3.36 & 0.24 & 1.0 & 10.6 & 39.2 & 80.9 & 92.9 \\
\hline \multirow[t]{2}{*}{ EI-2 } & 5 & 0.01 & 22.8 & 22.0 & 9.75 & 0.01 & 0.2 & 0.9 & 1.9 & 2.6 \\
\hline & 6 & 0.43 & 9.79 & 9.43 & 4.33 & 0.0 & 0.0 & 0.0 & 0.02 & 1.7 \\
\hline \multirow[t]{3}{*}{ EI-4 } & 7 & -0.04 & 1.90 & 0.88 & 0.07 & 6.9 & 71.1 & 94.4 & 99.5 & 99.9 \\
\hline & 8 & -0.05 & 1.8 & 1.17 & 0.08 & 9.0 & 65.8 & 93.1 & 98.5 & 99.8 \\
\hline & 9 & -0.03 & 1.38 & 0.61 & 0.07 & 11.2 & 68.0 & 93.7 & 99.8 & 99.98 \\
\hline \multirow[t]{2}{*}{ EI-5 } & 10 & 0.20 & 11.94 & 7.17 & 0.69 & 0.0 & 0.0 & 0.01 & 11.8 & 81.0 \\
\hline & 11 & 0.00 & 6.72 & 6.16 & 0.50 & 0.08 & 8.5 & 23.1 & 50.6 & 80.8 \\
\hline \multirow[t]{2}{*}{ CB-1 } & 12 & -0.02 & 5.69 & 3.49 & 0.95 & 0.07 & 0.7 & 3.7 & 14.3 & 56.6 \\
\hline & 13 & -0.05 & 0.88 & 0.74 & 0.21 & 3.1 & 19.9 & 49.7 & 98.0 & 100 \\
\hline \multirow[t]{2}{*}{ CB-2 } & 14 & 0.00 & 1.95 & 1.10 & 0.2 & 0.3 & 10.0 & 51.4 & 96.1 & 99.8 \\
\hline & 15 & -0.03 & 2.18 & 1.04 & 0.16 & 0.6 & 21.3 & 70.2 & 98.2 & 99.9 \\
\hline \multirow[t]{3}{*}{ CB-3 } & 16 & 0.06 & 12.02 & 11.14 & 0.38 & 0.0 & 0.1 & 5.2 & 64.9 & 78.8 \\
\hline & 17 & 1.14 & 13.86 & 12.87 & 1.51 & 0.0 & 0.0 & 0.0 & 0.0 & 0.0 \\
\hline & 18 & 0.15 & 14.28 & 13.65 & 2.56 & 0.0 & 0.0 & 0.02 & 0.6 & 4.6 \\
\hline
\end{tabular}



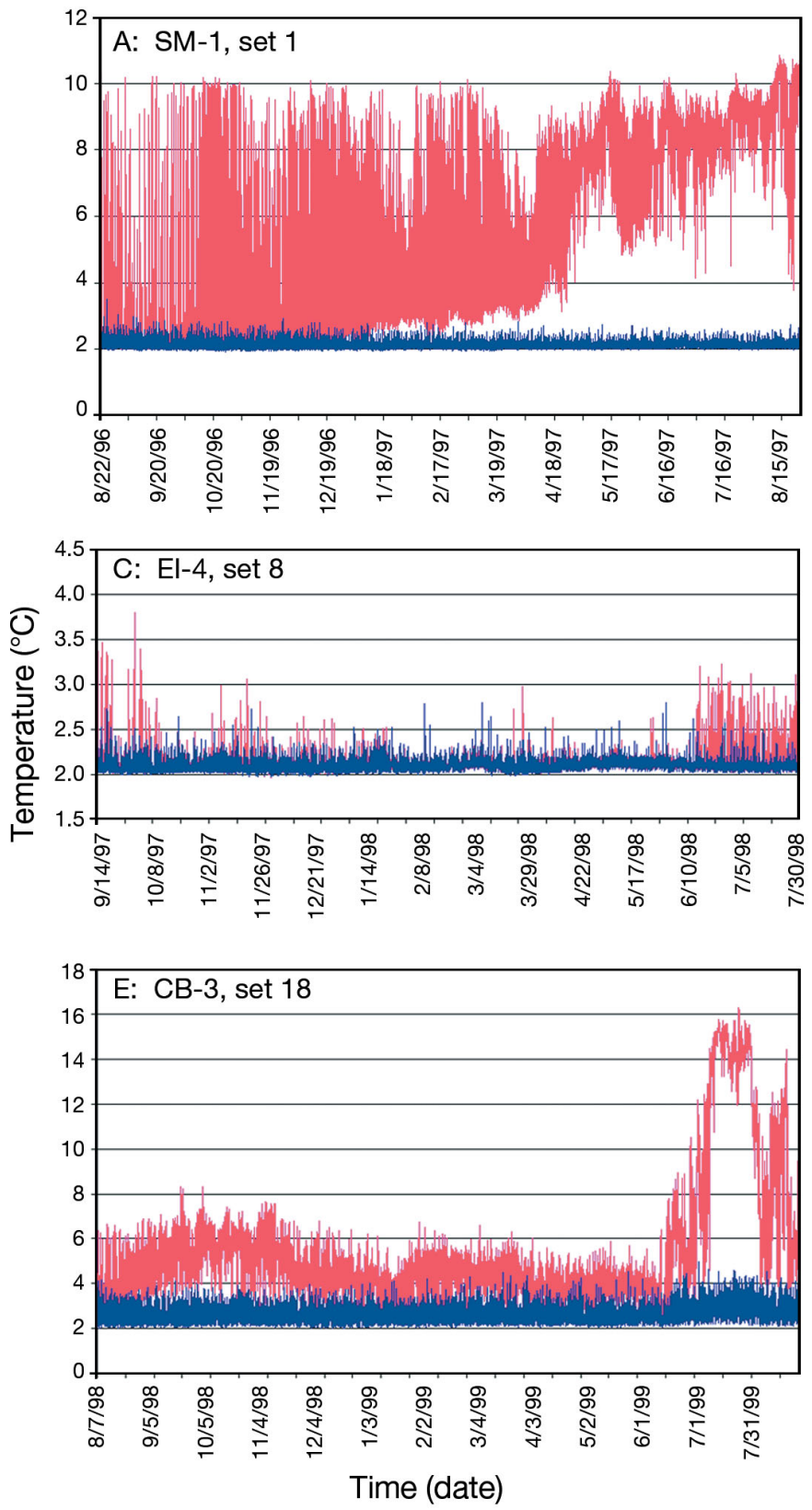

$<0.2^{\circ} \mathrm{C}$ above ambient. Temperatures recorded by 13 of the 18 probes placed at the plume level were $\leq 1^{\circ} \mathrm{C}$ above ambient $99 \%$ of the time, and temperature recorded by two-thirds of the probes were $\leq 0.5^{\circ} \mathrm{C}$ above ambient $95 \%$ of the time (Table 2). By comparison, base-level probes consistently recorded significantly higher temperatures than the corresponding plume-level probes, as would be expected in an environment where the warm water is emanating from the substratum ( $p<0.001$ in all comparisons of paired plume-base probes; Table 2). In several cases, virtually all the temperatures recorded were consistently higher than ambient, indicating that they had been
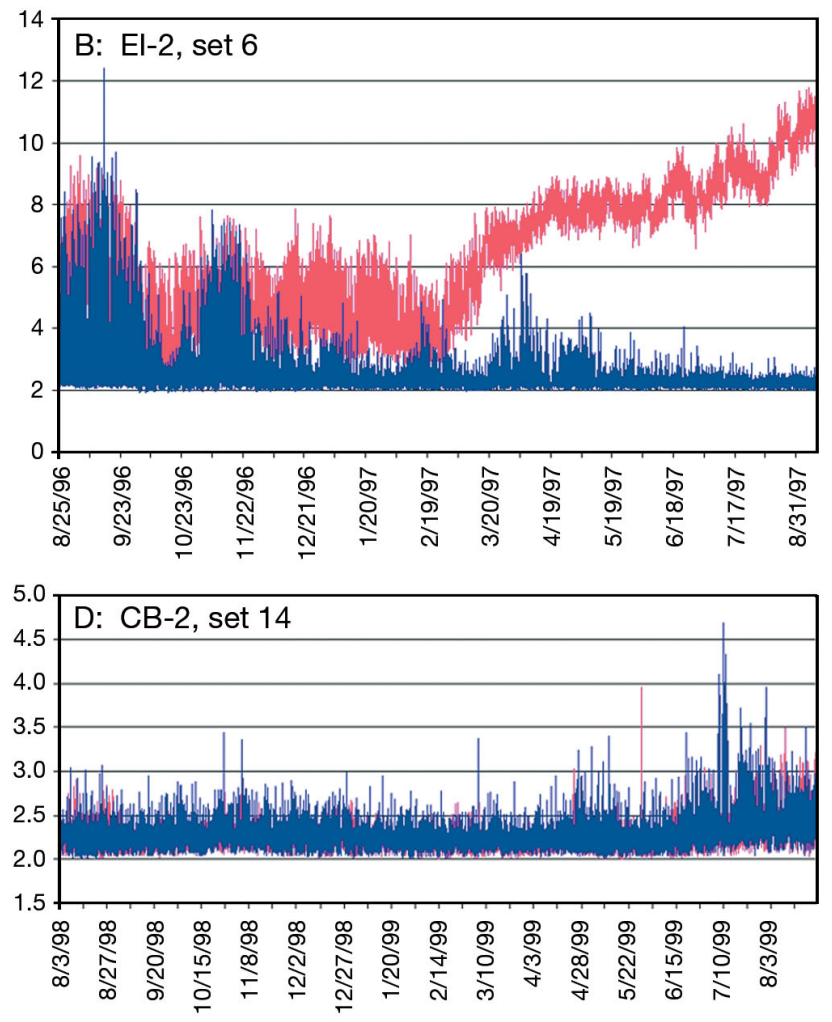

Base-level $\longrightarrow$ Plume-level

Fig. 4. Ridgeia piscesae. Year-long time-series of temperature data from aggregations of the tubeworm. (A) Temperature record from Thermistor Set 1, showing near ambient temperatures at the plume level and higher temperatures at the base level, with consistently large temperature fluctuations. (B) Temperature record from Thermistor Set 6, showing significantly and consistently higher base-level temperatures together with high temperature anomalies at the plume level. (C) Temperature record from Thermistor Set 8 showing very low temperatures (usually very near ambient) at both the plume and base levels. (D) Temperature record from Thermistor Set 14, also showing the small temperature fluctuation from ambient in both plume- and base-level locations. (E) Temperature record from Thermistor Set 18, showing consistently higher temperatures at the base level and increased temperatures after seismic activity in June 1998. Dates given as mm/dd/yy

placed in the immediate vicinity of a source of diffuse flow on the sea floor (Fig. 4A,B,E). The 3 base-level probes placed in EI-4 had records similar to those recorded for their paired plume-level probes; this was also the case for Pairs 13 to 16 at CB (Fig. 4C,D). Nested ANOVA showed that plume-level median temperatures varied significantly between sites $\left(F_{1,8}=\right.$ 7.73, $\mathrm{p}=0.049$ ), but only varied marginally between aggregations within sites $\left(F_{4,8}=3.29, \mathrm{p}=0.071\right)$. Median base-level temperatures did not vary significantly between sites $\left(F_{1,8}=0.070, \mathrm{p}=0.808\right)$, but did vary significantly between aggregations within sites $\left(F_{4,8}=16.26, \mathrm{p}=0.001\right)$. 
Using the full dataset, temperatures recorded at the plume level at CB-3 were significantly higher than the temperatures recorded in association with any other aggregation at CB ( $p<0.001)$, but no differences were found at the plume level among aggregations at EI ( $p>$ 0.05). At EI, the base-level temperatures at EI-2 were significantly higher than in any other aggregation at EI ( $p<0.001$ ), and at CB the base-level temperatures at CB-3 were significantly higher then the others at that site $(\mathrm{p}<0.001)$. Plume- and base-level temperatures were also significantly different between sites in the full dataset. Median temperatures recorded at the plume level from the 3 sites were significantly different from one another (CB $>$ S\&M $>$ EI, $\mathrm{p}<0.001$ for all comparisons). This site-to-site difference was still significant when the records from CB-3 were not included in the analysis. Base-level median temperatures from the 3 sites were also significantly different from one another (EI $>$ S\&M $>C B$; $<0.001$ for all comparisons).

Sulfide was always detected from water samples taken at the base level in the aggregations at EI $(2.72$ to $24.18^{\circ} \mathrm{C}$ ), but was not detected from samples taken at the plume level $\left(1.96\right.$ to $\left.2.92^{\circ} \mathrm{C}\right)$. At the $\mathrm{CB}$ site, sulfide was detected in all water samples taken at the base level $\left(6.59\right.$ to $\left.36.0^{\circ} \mathrm{C}\right)$ and was detected in $60 \%$ of samples taken at the plume level $\left(2.26\right.$ to $\left.4.24^{\circ} \mathrm{C}\right)$. Temperature and sulfide were positively correlated in the water samples taken at both EI and CB, but the linear relationship between sulfide and temperature was significantly different at the 2 sites (Fig. 5). At EI, the relationship was relatively tight $\left(\mathrm{H}_{2} \mathrm{~S}[\mu \mathrm{M}]=7.97\right.$ $\times$ Temp $\left.\left[{ }^{\circ} \mathrm{C}\right]-18.2, \mathrm{n}=9, \mathrm{R}^{2}=98.5, \mathrm{df}=8, \mathrm{p}<0.001\right)$, while it was considerably more variable at $\mathrm{CB}\left(\mathrm{H}_{2} \mathrm{~S}\right.$ $[\mu \mathrm{M}]=28.2 \times \operatorname{Temp}\left[{ }^{\circ} \mathrm{C}\right]-51.4, \mathrm{n}=9, \mathrm{R}^{2}=80.3, \mathrm{df}=8$, $\mathrm{p}=0.001)$.

\section{Tubeworm growth}

There was no evidence that the staining process affected tubeworm growth. During staining, the tubeworms retracted inside their tubes and their soft tissues were only minimally exposed to the dye solution. On follow-up dives, stained tubeworms were observed behaving much like their unstained neighbors; they would retreat into their tubes when exposed to physical stimuli and later re-emerge. In all likelihood, if there were drastic effects (positive or negative) on tubeworm growth due to the staining procedure, we would have expected to observe resulting differential growth between stained and the adjacent non-stained groups in the same aggregation (for example, a group of stained individuals surrounded by visually taller non-stained individuals at the end of the same study period). However, no such differences were seen in the

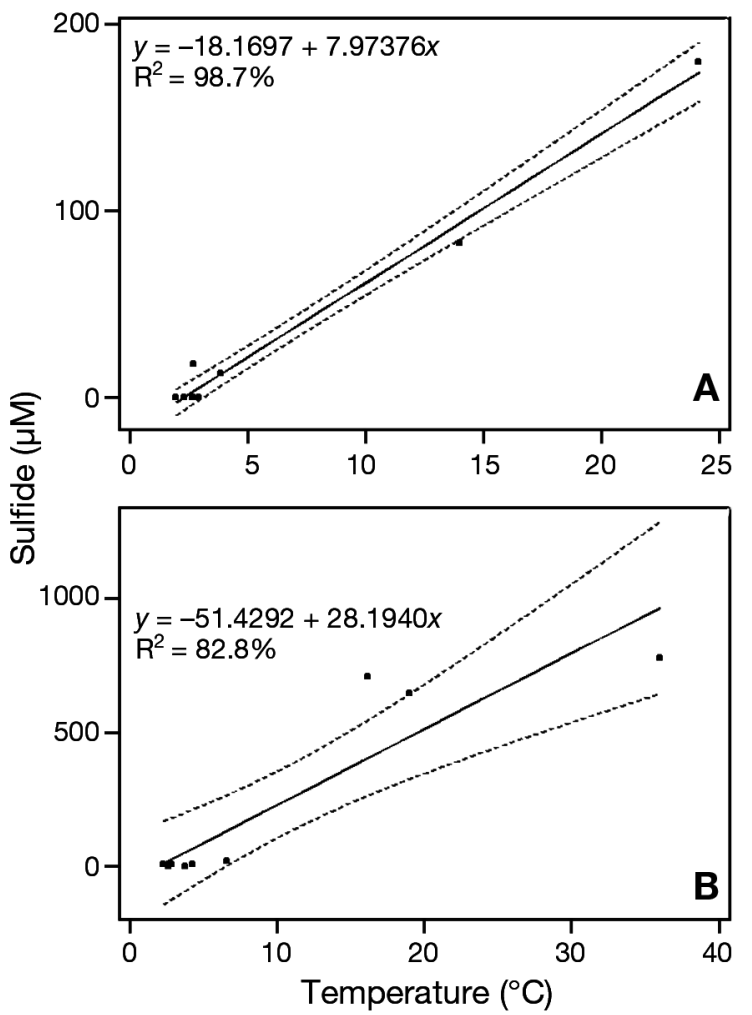

Fig. 5. Ridgeia piscesae. Relationships between temperature and sulfide from water samples obtained in 1999 around tubeworm aggregations at (A) Easter Island and (B) Clam Bed vent sites. Dashed lines: $95 \%$ confidence intervals

extensive video records of any of the stained aggregations. This same staining technique has also been successfully used to monitor the growth rates of 2 related species from hydrocarbon seeps in the GoM, with no discernable effect on their growth or mortality (Bergquist et al. 2002).

Growth rate did not vary significantly with initial tube length in the pooled dataset, which included all stained animals with posterior OD $\leq 0.12 \mathrm{~cm}$ (Fig. 6). Within 2 of the 10 aggregations, growth rate varied significantly with initial tube length $(p<0.003)$. In the case of EI-6 (the largest individual dataset and the smallest animals), the relationship was negative (growth rate dTabnecreased with increasing tube length), while, in the case of EI-3, the relationship was positive (growth rate increased with increasing tube length).

The growth rates of the 536 stained and retrieved Ridgeia piscesae varied from no growth over a 2 yr period to over $25 \mathrm{~cm}$ in a single year (Table 3). Growth rates within individual aggregations were similarly variable and, in all but 1 aggregation, there were at least 2 individuals that did not grow over the course of the study. Two of the aggregations showed little varia- 
Fig. 6. Ridgeia piscesae. Relationship between size and yearly growth rates of the 'long-skinny' morphotype of $R$. piscesae in the present study. Tube size and tube growth rates of tubeworms generally clustered by aggregation of origin. No significant relationship was found between growth and initial size. Initial tube length represents the difference between total tube length and the length of the new tube growth. Vent site aggregations: EI, Easter Island; SM, Smoke andMirrors; CB, Clam Bed

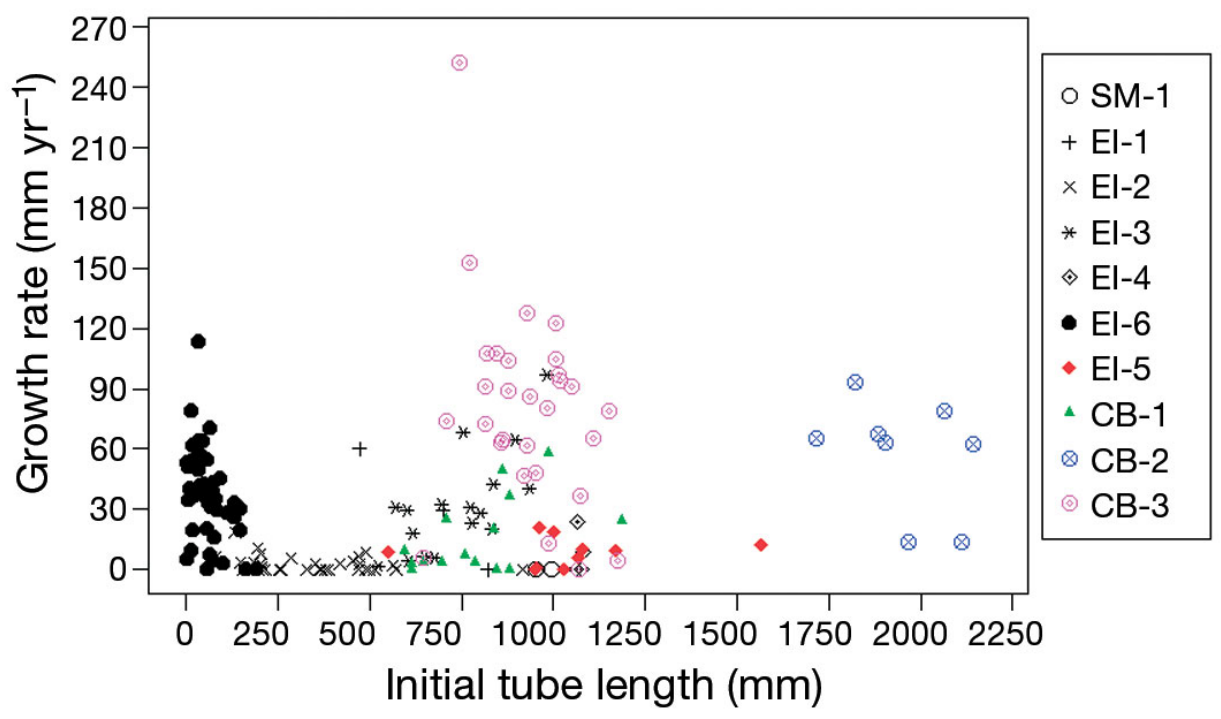

was monitored for 62 d laid down 2 increments, between which $17 \mathrm{~d}$ elapsed with no growth.

There was no significant difference in the growth rates of the double-stained individuals at either EI-5 or CB-1 between consecutive years, although all but 1 individual at CB-1 grew more the second year than the first year (Table 4). Because the stainer enclosed overlapping but distinct groups of tubeworms in the $2 \mathrm{yr}$ of staining, some animals at each site were stained only once. There was no significant difference in the growth rates of the blue-only stained animals and the doubly stained animals at EI-5 $(t=1.90, \mathrm{df}=18, \mathrm{p}=$ 0.074). The singly stained animals at CB-1 grew significantly less than the double-stained animals did in the second year (Year 1: $t=-1.05, \mathrm{df}=11, \mathrm{p}=0.32$; Year 2: $t=-3.29, \mathrm{df}=11, \mathrm{p}=0.007$; Table 4$)$. When data from both sites were pooled, there was a significant correlation between individual growth rates in Years 1 and 2 $(\mathrm{r}=0.809, \mathrm{p}<0.001)$. When the aggregations were considered individually, the correlation between individual growth rates in consecutive years was only significant within EI-5 ( $\mathrm{r}=0.696, \mathrm{p}=0.017)$.

Ridgeia piscesae growth rate varied significantly between sites $\left(F_{1,519}=6.63, \mathrm{p}=0.033\right)$ and between aggregations within a site $\left(F_{8,519}=25.74, \mathrm{p}<0.001\right)$. Growth rates were significantly different between EI and $\mathrm{CB}\left(F_{1,7}=8.26, \mathrm{p}<0.024\right.$; Table 3$)$. No animals grew at SM-1. Within the EI vent site, the growth rates of the 6 aggregations fell into 2 groups, with individuals in 3 aggregations growing relatively slowly (averaging 0.3 to $0.9 \mathrm{~cm} \mathrm{yr}^{-1}$ ) and individuals in 3 others growing rather quickly (averaging 2.7 to $4.0 \mathrm{~cm} \mathrm{yr}^{-1}$ ) (Table 3). At CB, 2 of the groups (CB-2 and -3 , which were located in the same large aggregation) grew significantly faster than CB-1 ( $p<0.001)$. 


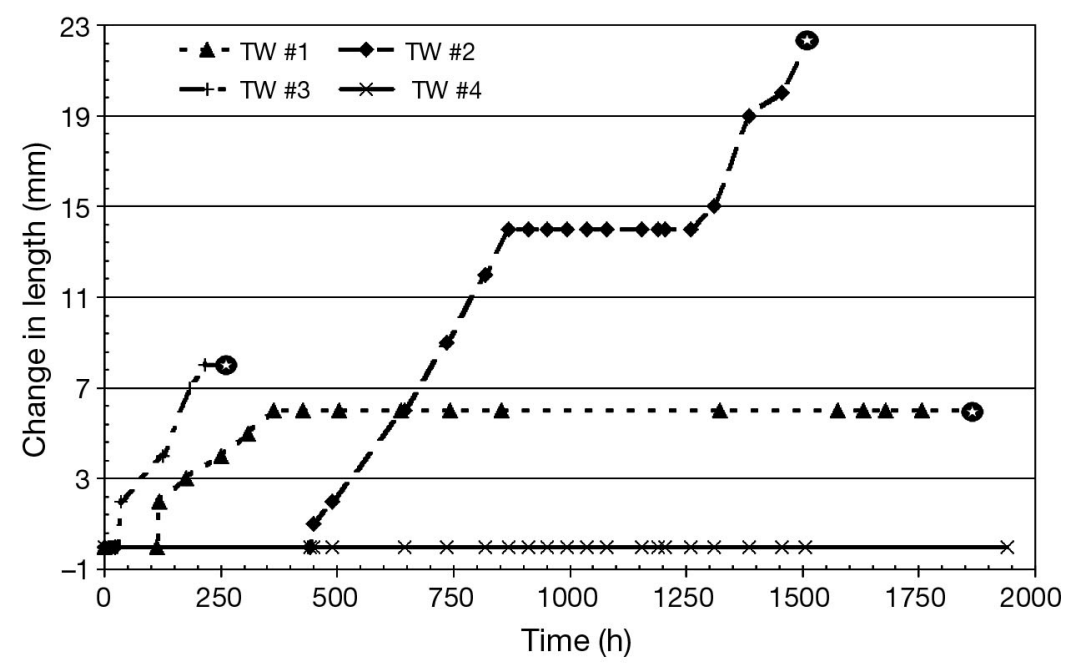

Fig. 7. Ridgeia piscesae. Tube growth documented by time-lapse photography. Time origin is the first frame taken on 16 July 1994. Average outer diameter $(5 \mathrm{~mm})$ of the top 13 increments from 6 different collected individuals from this aggregation was used for scale purposes. White star: time when the stained individual tubeworm was lost from the picture frame; TW \#1 to TW \#4: the 4 tubeworm individuals that were followed with the time-lapse image analysis

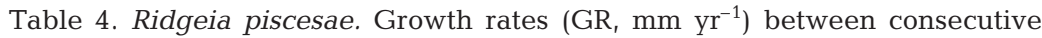
years from double- and single-stained individuals within the same aggregations. Values associated with different letters indicate significant differences in 2 -sample $t$-test comparisons within the same vent site. Calendar years between staining and collection are indicated in the third column. B: blue stained only; B+R: blue and red stained; R: red stained only; Agg.: aggregations; $n$ : number of individuals

\begin{tabular}{|lccccc|}
\hline Site & Agg. & $\begin{array}{c}\text { Staining color } \\
\text { (growth years) }\end{array}$ & $\mathrm{n}$ & Range & Mean \pm SD \\
\hline Easter Island & EI-5 & B (1997-1999) & 31 & $0-43.4$ & $9.9 \pm 9.9^{\mathrm{a}}$ \\
& & B+R (1997-1998) & 11 & $0-16$ & $4.9 \pm 5.8^{\mathrm{a}}$ \\
& & B+R (1998-1999) & & $0-12.4$ & $5.7 \pm 4.9^{\mathrm{a}}$ \\
& & $\mathrm{R}(1998-1999)$ & 0 & - & - \\
Clam Bed & $\mathrm{CB}-1$ & $\mathrm{~B}(1996-1998)$ & 19 & $0-64.6$ & $24.8 \pm 18.3^{\mathrm{a}}$ \\
& & $\mathrm{B}+\mathrm{R}(1996-1997)$ & 8 & $0-69.0$ & $37.7 \pm 23.6^{\mathrm{a}, \mathrm{b}}$ \\
& & $\mathrm{B}+\mathrm{R}(1997-1998)$ & & $24.5-157.8$ & $66.6 \pm 42.9^{\mathrm{b}}$ \\
& & $\mathrm{R}(1997-1998)$ & 25 & $0-93.2$ & $26.6 \pm 26.7^{\mathrm{a}}$ \\
\hline
\end{tabular}

\section{DISCUSSION}

\section{Habitat}

Although there is considerable temperature variability within and between the aggregations, when all the temperature data are considered, a generalized habitat occupied by the long-skinny growth form of Ridgeia piscesae emerges. Temperatures around the plumes of this morphotype are normally $<1^{\circ} \mathrm{C}$ above ambient; in fact, for many individuals plume-level temperatures never exceed $1^{\circ} \mathrm{C}$ above ambient (Table 2). Over $95 \%$ of the temperatures recorded at the plume level by two-thirds of the thermistors were $<0.5^{\circ} \mathrm{C}$ above ambient, and the median temperatures recorded by all of those thermistors were $<0.2^{\circ} \mathrm{C}$ above ambient. In the most thermally active aggregations monitored (which were originally chosen because they were the most visually active aggregations seen in this area), the maximum temperatures measured around the plumes of the tubeworms were $6^{\circ} \mathrm{C}$ above ambient and the median temperature anomalies were all $<1^{\circ} \mathrm{C}$. However, the median temperatures in all plumelevel records were above ambient (the lowest was $0.05^{\circ} \mathrm{C}$ above ambient), which indicates that the animals are exposed to very diluted vent fluid around their plumes at least half of the time. Temperatures recorded near the basaltic substratum within the aggregations were even more variable, but were still relatively low (Table 2). At one extreme were the temperatures recorded at the base level in aggregation EI-4 at EI, where all 3 thermistors records resembled those from the plume level, with about $99 \%$ of the temperatures within $0.5^{\circ} \mathrm{C}$ above ambient and median temperature anomalies $<0.1^{\circ} \mathrm{C}$. At the opposite extreme were temperatures like those recorded at the base of EI-2, which rarely or never reached ambient temperatures and ranged as high as 10 to $22^{\circ} \mathrm{C}$ above ambient.

Comparison of the temperature records from base and plume pairs suggests that the flow rate of the warm water exiting the substratum is low relative to other well-characterized vent tubeworm habitats (Table 2). For example, the 2 base thermistors at EI-2 recorded median temperatures of 9.8 and $4.3^{\circ} \mathrm{C}$ above ambient, and yet the corresponding plume-level thermistors, only $36 \mathrm{~cm}$ above, recorded median temperatures of 0.1 and $0.3^{\circ} \mathrm{C}$ above ambient and maximum temperature anomalies of 1.2 and $6.5^{\circ} \mathrm{C}$. These thermal parameters indicate a habitat that is very different from that of EPR tubeworms or the short-fat morphotype of Ridgeia piscesae from the JdFR, which are normally exposed to higher temperatures and relatively vigorous, diffuse vent flow at the plume level (Hessler et al. 1988, Mullineaux et al. 2000). The maximum temperature recorded 'near the worms' in a combined aggregation of the EPR 
tubeworm Riftia pachyptila with the mussel Bathymodiolus thermophilus during a $3 \mathrm{~d}$ deployment was $14.8^{\circ} \mathrm{C}$, with a mean of $5.5^{\circ} \mathrm{C}$ (Johnson et al. 1988a). Martineu et al. (1997) report a temperature range of 9.1 to $44.3^{\circ} \mathrm{C}$ within the Strawberry Fields aggregation of the short-fat morphotype of $R$. piscesae on top of the $\mathrm{S} \& \mathrm{M}$ sulfide structure at the JdFR. Maximum temperatures around the plume level of $R$. pachyptila ranged from 2.9 to $14^{\circ} \mathrm{C}$ (Johnson et al. 1988b). By comparison, during the $4 \mathrm{yr}$ in which the long-skinny morphotype was monitored in this study, the maximum plume-level temperatures ranged from 2.5 to $9.7^{\circ} \mathrm{C}$. Shank et al. (1998) reported that the maximum temperatures around the bases of aggregations of $R$. pachyptila and Tevnia jerichonana from the EPR were between 16 and $35^{\circ} \mathrm{C}$ (discrete measurements from the 'Alvin' temperature probe). This reported range of base-level maximum temperatures is narrower and higher than the range of maximum temperatures recorded at the bases of S\&M, EI and CB aggregations $\left(2.9\right.$ to $\left.24.8^{\circ} \mathrm{C}\right)$. Based on these comparisons, it is apparent that the longskinny morphotype of $R$. piscesae from the JdFR is exposed to consistently lower temperatures than $R$. pachyptila and T. jerichonana from the EPR.

The range and spatial distribution of temperatures indicate that there is a high degree of heterogeneity, at both plume and base levels within the same aggregations. For example, data from plume-level temperature probes located within $10 \mathrm{~cm}$ of each other at EI-2 show no evidence of coupling of either short- or long-term changes in their corresponding temperature records. This indicates that plumes of vent tubeworms separated by a few centimeters can be experiencing very different levels of exposure to the diffuse vent flow. The spatial and temporal variability of temperature regimes within aggregations is very likely influenced by the physical attributes of the fluid source, the strength and original temperature of the flow, the position of the source relative to the location of the aggregation and the density of the tubeworm aggregation.

Sulfide and temperature were significantly correlated within each vent site, and the relationship was significantly different between the sites. Numerous studies have shown that the temperature of the vent fluid is a reliable indicator of relative hydrogen sulfide concentrations within a vent field (Johnson et al. 1986, 1988a,b, Massoth et al. 1989, 1994, Butterfield et al. 1994, Sarradin et al. 1998). The finding of a significantly different relationship between temperature and sulfide in diffuse flow at EI and CB is reasonable, since hightemperature vent-fluid chemical composition varies among vents on the Endeavour Segment, and the shallow subsurface mixing regimes of these 2 sites are very likely separate (Von Damm \& Bischoff 1987, Butterfield et al. 1990, 1994). Tubeworms within the EI site are con- sistently exposed to very low levels of diffuse vent flow (median range $=0.05$ to $0.27^{\circ} \mathrm{C}$ above ambient), and, within the $\mathrm{CB}$ vent site, the animals are exposed to higher levels of diffuse vent flow (median range $=0.15$ and $0.85^{\circ} \mathrm{C}$ above ambient). This, coupled with the different sulfide-temperature relationships of the 2 sites, indicates that the CB tubeworms are generally exposed to substantially higher sulfide levels than those at EI. In fact, the temperature-sulfide relationships suggest that no sulfide is present in the median temperature water around the plumes of tubeworms at EI, while the median sulfide levels around the plumes of the CB worms are 11 to $23 \mu \mathrm{M}$. This is further corroborated by the fact that sulfide was never detected in the plume-level water samples at EI, but was detected in $60 \%$ of the plume-level samples from CB (detection limit is $\sim 5 \mu \mathrm{M}$ ).

\section{Tubeworm growth and environmental effects}

Ridgeia piscesae growth rates varied, often over a wide range, among individuals in the same aggregation. Within the relatively small spatial area occupied by the groups of stained organisms in each aggregation (staining areas are $<25 \mathrm{~cm}$ in diameter), there were individual tubeworms that did not grow over the entire time period, as well as individuals that showed the highest documented growth rates in this study. At EI-6, for example, 12 tubeworms (out of a total of 127) did not grow, while 3 individuals in the same aggregation grew $>10 \mathrm{~cm}$ during the same period. At CB-3, 6 individuals (out of a total of 111) did not grow, while 25 individuals in the same aggregation grew $>10 \mathrm{~cm}$, one of which grew $25 \mathrm{~cm}$ during the same period. Similar variability in growth rate within an aggregation was apparent between adjacent tubeworms in one of the doubly stained aggregations, CB-1 (Table 4). The only aggregation that did not show marked variability in growth rates was SM-1, where no animals grew over the entire period of observation. The high growth rate heterogeneity within the same aggregations may be explained by the heterogeneity of the microenvironment around the plumes of the tubeworms. Alternatively, it may also be due to interspecific competition for sulfide acquisition. Even considering the above, the lack of a significant overall relationship between animal size and growth rate in this study was unexpected. Although this does not necessarily indicate that a biologically based allometric relationship between size and growth rate does not exist in this tubeworm species, it may be indicative of the relative importance of the environment to the growth of $R$. piscesae.

The mean annual growth rates of Ridgeia piscesae in this study were much lower than previously reported for EPR tubeworms or other morphotypes of 
R. piscesae (Table 3). The tubes of Riftia pachyptila from the EPR have been documented to grow as fast as $\sim 85 \mathrm{~cm} \mathrm{yr}^{-1}$, and this species has been suggested to be one of the fastest growing invertebrates on the planet (Lutz et al. 1994, Shank et al. 1998). Another EPR species, Tevnia jerichonana, also grows fast $\left(\sim 30 \mathrm{~cm} \mathrm{yr}^{-1}\right)$ (Lutz et al. 1994, Shank et al. 1998). $R$. piscesae can sustain fast growth rates ranging from 6 to $95 \mathrm{~cm} \mathrm{yr}^{-1}$ under favorable conditions (Tunnicliffe et al. 1990, 1997, Sarrazin et al. 1997, Urcuyo et al. 1998). However, $R$. piscesae can also survive and grow very slowly when exposed to low levels of vent flow and sulfide (Tables $2 \& 3$ ). The capability for relative fast or slow growth, largely independent of size, would be beneficial for a vent tubeworm such as $R$. piscesae. Detrimental changes in the immediate vent environment, such as the temporary slow down or shutdown of diffuse flow venting, can be better managed by an animal that can slow or arrest their growth during these periods.

The time-lapse photographs show that anterior tube growth occurs as episodic 'growth spurts'. These growth episodes can last as long as $18 \mathrm{~d}$, followed by resting periods that can be as short as $17 \mathrm{~d}$ (Fig. 7). Each new anterior tube segment is deposited as a single, white, semi-translucent, cylinder-shaped increment. At the end of the growth period, a flare is added to the anterior-most end of the new section (the remains of the older, worn-out flares, are the visible ring markings on the exterior of Ridgeia piscesae tubes). The entire new anterior tube section appears to be reinforced, from the inside of the tube, over a longer period of time.

Even though the documented centimeter-scale microhabitat differences at the plume level within aggregations (resulting in different exposure to vent fluids) can potentially explain why nearby individuals do not show comparable growth rates, it does not explain the finding that between consecutive years, individual tubeworm growth rates within the same aggregations remain the same. The significant correlation between consecutive-year growth rates of the same individuals indicates that the immediate microenvironment (temperature and sulfide regimes) did not significantly change over the long-term, even though spatially there is high heterogeneity at the plume level as indicated by the temperature records. Like their seep relatives, this morphotype of Ridgeia piscesae possesses extensive root-like posterior tube sections, and the small-diameter, thin-walled posterior tube extensions are permeable to sulfide. These permeable sections are hypothesized to be the location of additional sulfide acquisition, in similarity to the findings from a recent study on GoM seep tubeworms (Freytag et al. 2001, Urcuyo et al. 2003). If animals of this morphotype are acquiring a significant portion of their endosymbiont sulfide requirements from a relatively reliable source near their posterior, this could explain the stable growth rates from year to year for those organisms whose roots are located near the vent source, regardless of the high variability of sulfide exposure at their plume level.

Overall, there was no statistically significant correlation between median plume-level temperatures and median tube growth rates or between estimated median sulfide levels and median tube growth rates (Spearman's rank correlation, $p>0.148$ ). This lack of correlation was unexpected and did not support the hypothesis that tubeworms exposed to higher levels of sulfide would have correspondingly higher growth rates. We consider 3 non-exclusive plausible explanations: (1) tube growth in this particular morphotype may actually be a result of changes in plume-level position associated with intraspecific competition for dissolved gasses, (2) individual tubeworm actual exposure to sulfide is much more complex and chaotic than the thermistor design could discern and (3) problems with the unbalanced design resulted in low statistical power unable to identify any potential effects of sulfide exposure on growth.

Rate of growth is often used as an indicator of general physiological condition, because it reflects the surplus energy available to an organism after allocating a basal amount to maintenance and reproduction (Ricklefs 1979). As much as $75 \%$ of the assimilated energy from food is channeled into growth and reproduction in most sedentary aquatic species (Welch 1968). However, this assumes that there are no negative effects of growth that might counteract the benefits of larger size (and presumably increased reproductive capacity). In the case of the sessile tubeworm living in the dynamic vent environment: Is there a potential negative effect caused by growth? In the well-studied species Riftia pachyptila, the plume is the gas exchange organ and it is the primary site for exchange of the necessary dissolved gasses, oxygen, sulfide and carbon dioxide (Childress \& Fisher 1992). Although it has been hypothesized that, like the cold seep relatives, Ridgeia piscesae can supplement sulfide uptake across permeable posterior portions of its body (Julian et al. 1999, Urcuyo et al. 2003), the plume (gills) of $R$. piscesae is still presumably the only significant location for uptake of oxygen and the primary location for uptake of carbon dioxide and sulfide. Therefore, positioning the plume such that it is exposed to both oxygen and sulfide is an important consideration for a vent tubeworm, and growth that would remove the plume from the correct microenvironment would be deleterious to the physiological balance of the symbiosis and could negate any benefits of larger size. This consideration 
could be especially significant to aggregations growing in situations of very diffuse flow, such as many of the aggregations in this study. If the individual tubeworm is acquiring a significant amount of its sulfide requirements from the posterior sections (when located closer to the source of vent fluid), then the life-time tube growth may represent adjustments in position to facilitate access to and acquisition of dissolved oxygen and carbon dioxide. This is an intriguing question that merits further studies and experimentation.

The L-shape design of each set of thermistor was initially decided upon based on the assumption that it would provide an accurate measurement of plumeand base-level exposure to vent fluid. However, the chaotic nature of the vent fluid mixing with ambient seawater coupled with the advective nature of the flow from the substrate and the undetermined location(s) of the sources within and around each aggregation could have obscured any influence of sulfide exposure (as measured by vent fluid temperature) on animal growth. Size, density and relative distribution of tubeworms within the aggregations have a direct effect on the mixing and oxidation of vent fluid and therefore also an impact on the exposure to sulfide. The longterm temperature data collected in this study clearly indicate the extreme microhabitat heterogeneity within aggregations and simultaneously underscore the need for more extensive sampling and conceptual modeling of vent fluid dynamics within relatively short spatial and temporal scales.

\section{Aggregation longevity}

Age calculations based on the mean growth rates of all the tubeworms in this study would be inappropriate. These types of calculations could only be done under the unsupported assumptions that their growth has remained the same over their entire life cycle and that there have not been any environmental changes that could have caused corresponding changes in growth. Our current understanding of the geology and biology of the vent ecosystem does not provide support for such specific assumptions (Baker et al. 1987, Hessler et al. 1988, Tunnicliffe et al. 1990, Lutz et al. 1994, Johnson et al. 2000). However, by taking only the top $10 \%$ of the growth rates from each aggregation together with their respective average total tube length, conservative minimum age estimates can be calculated for the aggregations involved in this study. Based on those calculations, the minimum age in aggregations at EI ranges from 1 (EI-6) to 37 yr old (EI-5). In the $\mathrm{CB}$ vent site, the minimum age in the 3 aggregations ranges from 6 (CB-1) to $17 \mathrm{yr}$ old (CB-2). The minimum age in most of the aggregations involved in this study ranges from 10 to $30 \mathrm{yr}$ and could be considerably older. The capacity of Ridgeia piscesae to survive for extended periods of time with no tube growth, as demonstrated by tubeworms in the SM-1, EI-2, EI-5 and CB-1 aggregations, makes these minimum estimations even more conservative. Therefore, it is reasonable to conclude that $R$. piscesae in diffuse flow basaltic habitats can live for decades, and can persist significantly longer than EPR tubeworm species (Juniper \& Tunnicliffe 1997, Shank et al. 1998).

The consistently low temperature anomalies recorded at the plume level of the majority of individuals in aggregations in this study clearly indicate that the long-skinny morphotype of Ridgeia piscesae can tolerate and live in habitats where vent flow and sulfide availability are quite low. The range of growth rates measured for this long-skinny growth form, together with the growth rates reported by others for this species (Tunnicliffe 1990, Sarrazin et al. 1997, Tunnicliffe et al. 1997), indicate that $R$. piscesae is capable of growth rates that span the range from the fast-growing EPR species (Riftia pachyptila and Tevnia jerichonana) to the very slow-growing GoM cold-seep species, such as Lamellibrachia cf. luymesi (Fisher et al. 1997, Bergquist et al. 2002). The ability of $R$. piscesae to survive and thrive under a wide range of environmental conditions with faster/slower growth is a key adaptation that allows this 1 single species of vent tubeworm to exploit many of the different microhabitats available at northeast Pacific hydrothermal vents.

Acknowledgements. The authors thank the captains and crews of the research vessels 'J. P. Tulley', 'T. G. Thompson' and 'Atlantis', and the pilots and engineers of the ROV 'ROPOS' and DSRV 'Alvin', without whose skills this kind of research would not be possible. Thanks also to C. Tietze and the Harbor Branch Oceanographic Institution Engineering Division for the design and construction of the tubeworm staining device. Thanks to Dr. V. Tunnicliffe for providing the use of the time-lapse camera and review of an earlier version of this manuscript. Thanks to Dr. T. Williams for insightful discussions; to 3 anonymous reviewers for their comments; to Dr. K. T. Scott, Dr. S. Hourdez, Dr. J. Sarrazin, V. Robigou, J. Marcus, M. Tsurumi, J. Kayes and the REVEL teachers K. Heidenreich, K. Wilson, S. Ivey, W. Kooi, A. Waring, J. Hojnowski and M. Williams for assistance at sea; and to J. T. Eckner, J. Bubb, T. Pundiak, P. Murray, A. Podey, J. Dohanich, A. Mondelblatt, A. Genson, W. Gomero and H. Tubbs for assistance in the laboratory. This work was supported by the NOAA West Coast National Undersea Research Center, NSF grants EAR-9158113 and OCE-9633105 to C.R.F., and the NSF REVEL program.

\section{LITERATURE CITED}

Baker ET, Massoth GJ, Feely RA (1987) Cataclysmic hydrothermal venting on the Juan de Fuca Ridge. Nature 329: 149-151 
Bergquist DC, Williams FM, Fisher CR (2000) Long life in the deep-sea. Nature 403:499-500

Bergquist DC, Urcuyo IA, Fisher CR (2002) Establishment and persistence of seep vestimentiferan aggregations on the upper Louisiana slope of the Gulf of Mexico. Mar Ecol Prog Ser 241:89-98

Black MA (1991) Genetic (allozyme) variation in Vestimentifera (Ridgeia sp.) from hydrothermal vents of the Juan de Fuca Ridge (northeast Pacific Ocean). MS thesis, University of Victoria

Bright M, Keckeis H, Fisher CR (2000) An autoradiographic examination of carbon fixation, transfer and utilization in the Riftia pachyptila symbiosis. Mar Biol 136:621-632

Butterfield DA, Massoth GJ, McDuff RE, Lupton JE, Lilley MD (1990) The chemistry of phase separated hydrothermal fluids from ASHES vent field, Juan de Fuca Ridge. J Geophys Res 95:12895-12922

Butterfield DA, McDuff RE, Mottl JJ, Lilley MD, Lupton JE, Massoth GJ (1994) Gradients in the composition of hydrothermal fluids from the Endeavour Segment vent field: phase separation and brine loss. J Geophys Res 99: 9561-9583

Cavanaugh CM, Gardiner SL, Jones JL, Jannasch HW, Waterbury JB (1981) Prokaryotic cells in the hydrothermal vent tube worm Riftia pachyptila Jones: possible chemoautotrophic symbionts. Science 213:340-342

Childress JJ, Fisher CR (1992) The biology of hydrothermal vent animals: physiology, biochemistry, and autotrophic symbioses. Oceanogr Mar Biol Annu Rev 30:337-441

Childress JJ, Arp AJ, Fisher CR (1984) Metabolic and blood characteristics of the hydrothermal vent tubeworm Riftia pachyptila. Mar Biol 83:109-124

Childress JJ, Felbeck H, Somero GN (1987) Symbiosis in the deep sea. Sci Am 256:114-120

Delaney JR, Robigou V, McDuff RE, Tivey MK (1992) Geology of a vigorous hydrothermal system on the Endeavour Segment, Juan de Fuca Ridge. J Geophys Res 97:19663-19682

Felbeck H (1981) Chemoautotrophic potential of the hydrothermal vent tube worm, Riftia pachyptila Jones. Science 213:336-338

Fisher CR, Childress JJ, Arp AJ, Brooks JM and 7 others (1988) Physiology, morphology and biochemical composition of Riftia pachyptila at Rose Garden in 1985. Deep-Sea Res A 35:1745-1758

Fisher CR, Urcuyo IA, Simpkins MA, Nix E (1997) Life in the slow lane: growth and longevity of cold-seep vestimentiferans. PSZN I: Mar Ecol 18:83-94

Freytag JK, Girguis PR, Bergquist DC, Andras JP, Childress JJ, Fisher CR (2001) Sulfide acquisition by roots of seep tubeworms sustains net chemoautotrophy. Proc Natl Acad Sci USA 98:13408-13413

Hessler RR, Smithey WM, Boundrias MA, Keller CH, Lutz RA, Childress JJ (1988) Temporal change in megafauna at the Rose Garden hydrothermal vent (Galapagos Rift; eastern tropical Pacific). Deep-Sea Res A 35:1681-1709

Johnson HP, Hutnak M, Dziak RP, Fox CG, Urcuyo I, Fisher C, Cowen JP, Nabelek J (2000) Earthquake-induced changes in a hydrothermal system at the Endeavour Segment; Juan de Fuca Ridge. Nature 407:174-177

Johnson KS, Beehler CL, Sakamoto-Arnold CM, Childress JJ (1986) In situ measurements of chemical distributions in a deep-sea hydrothermal vent field. Science 231:1139-1141

Johnson KS, Childress JJ, Beehler CL (1988a) Short-term temperature variability in the Rose Garden hydrothermal vent field: an unstable deep-sea environment. Deep-Sea Res A 35:1711-1721

Johnson KS, Childress JJ, Hessler RR, Sakamoto-Arnold CM,
Beehler CL (1988b) Chemical and biological interactions in the Rose Garden hydrothermal vent field, Galapagos spreading center. Deep-Sea Res A 35:1723-1744

Julian D, Françoise G, Wood E, Arp AJ, Fisher C (1999) Roots as a site of hydrogen sulfide uptake in the hydrocarbon seep vestimentiferan Lamellibrachia sp. J Exp Biol 202: $2245-2257$

Juniper SK, Tunnicliffe V (1997) Crustal accretion and the hot vent ecosystem. Phil Trans R Soc Lond B 355:459-474

Juniper SK, Tunnicliffe V, Southward EC (1992) Hydrothermal vents in turbidite sediments on a Northeast Pacific spreading center; organisms and substratum at an ocean drilling site. Can J Zool 70:1792-1809

Lutz RA, Kennish MJ (1993) Ecology of deep-sea hydrothermal vent communities: a review. Rev Geophys 31:211-242

Lutz RA, Shank TM, Fornari DJ, Haymon RM, Lilley MD, Von Damm KL, Desbruyeres D (1994) Rapid growth at deepsea vents. Nature 371:663-664

MacDonald I, Fisher CR (1996) Life without light. Natl Geogr Mag 190:86-97

Martell KA, Tunnicliffe V, MacDonald IR (2002) Biological features of a buccinid whelk (Gastropoda, Neogastropoda) at the Endeavour ventfields of Juan de Fuca Ridge, northeast Pacific. J Molluscan Stud 68:45-53

Martineu P, Juniper SK, Fisher CR, Massoth GJ (1997) Sulfide binding in the body fluids of hydrothermal vent alvinellid polychaetes. Physiol Zool 70:578-588

Massoth GJ, Milburn HB, Hammond SR, Butterfield DA, McDuff RE, Lupton JE (1989) The geochemistry of submarine venting fluids at Axial Volcano, Juan de Fuca Ridge: new sampling methods and a vents program rationale. In: DeLuca MP, Babb I (eds) Global venting, midwater, and benthic ecological processes. National Undersea Research Program, Silver Springs, MD, p 29-59

Massoth GJ, Baker ET, Lupton JE, Freely RA, Butterfield DA, VonDamm KL, Roe KK, Lebon GT (1994) Temporal and spatial variability of hydrothermal manganese and iron at Cleft Segment, Juan de Fuca Ridge. J Geophys Res 99: 4905-4924

Mullineaux LS, Fisher CR, Peterson CH, Schaeffer SW (2000) Tubeworm succession at hydrothermal vents: Use of biogenic cues to reduce habitat selection error? Oecologia 123:275-284

Ricklefs RE (1979) Ecology. Chiron Press, New York

Sarradin PM, Caprais JC, Briand P, Gaill F, Shillito B, Desbruyeres D (1998) Chemical and thermal description of the environment of the Genesis hydrothermal vent community (13 degrees N, EPR). Cah Biol Mar 39:159-167

Sarrazin J, Robigou V, Juniper SK, Delaney JR (1997) Biological and geological dynamics over four years on a hightemperature sulfide structure at the Juan de Fuca Ridge hydrothermal observatory. Mar Ecol Prog Ser 153:5-24

Shank TM, Fornari DJ, Von Damm KL, Lilley MD, Haymon RM, Lutz RA (1998) Temporal and spatial patterns of biological community development at nascent deep-sea hydrothermal vents $\left(9^{\circ} 50^{\prime} \mathrm{N}\right.$, East Pacific Rise). Deep-Sea Res A 45:465-515

Southward EC, Tunnicliffe V, Black M (1995) Revision of the species of Ridgeia from northeast Pacific hydrothermal vents, with a redescription of Ridgeia piscesae Jones (Pogonophora: Obturata = Vestimentifera). Can J Zool 73: 282-295

Tunnicliffe VM (1990) Effects of sampling on hydrothermal vent deposits and animals. J Geophys Res 95:12961-12966

Tunnicliffe V (1992) The nature and origin of the modern hydrothermal vent fauna. Palaios 7:338-350

Tunnicliffe V, Botros M, de Burgh ME, Dinet A, Johnson HP, 
Juniper SK, McDuff RE (1986) Hydrothermal vents of Explorer Ridge, northeast Pacific. Deep-Sea Res A 33: 401-412

Tunnicliffe V, Garret JF, Johnson HP (1990) Physical and biological factors affecting the behaviour and mortality of hydrothermal vent tubeworms (vestimentiferans). DeepSea Res A 37:103-125

Tunnicliffe V, Embley RW, Holden JF, Butterfield DA, Massoth G, Juniper SK (1997) Biological colonization of new hydrothermal vents following an eruption on Juan de Fuca Ridge. Deep-Sea Res A 44:1627-1644

Urcuyo IA, Massoth G, Macdonald I, Fisher CR (1998) In situ growth of the vestimentiferan Ridgeia piscesae living in highly diffuse vents in the main Endeavour Segment

Editorial responsibility: Otto Kinne (Editor-in-Chief), Oldendorf/Luhe, Germany of the Juan de Fuca Ridge. Cah Biol Mar 39:267-270 Urcuyo IA, Massoth GJ, Julian D, Fisher CR (2003) Habitat, growth and physiological ecology of a basaltic community of Ridgeia piscesae from the Juan de Fuca Ridge. DeepSea Res A 50:763-780

Van Dover CL, Lutz RA (2004) Experimental ecology at deepsea hydrothermal vents: a perspective. J Exp Mar Biol Ecol 300:273-307

Von Damm KL, Bischoff JL (1987) Chemistry of hydrothermal solutions from the southern Juan de Fuca Ridge. J Geophys Res 92:11334-11346

Welch H (1968) Relationships between assimilation efficiencies and growth efficiencies for aquatic consumers. Ecology 49:755-759

Submitted: March 5, 2003; Accepted: September 26, 2006 Proofs received from author(s): August 8, 2007 